\title{
Salmonella exploits suicidal behavior of epithelial cells
}

\author{
Sebastian E. Winter and Andreas J. Bäumler* \\ Department of Medical Microbiology and Immunology, University of California Davis, Davis, CA, USA \\ *Correspondence: ajbaumler@ucdavis.edu
}

Infection with enteric bacterial pathogens such as Salmonella leads to tissue invasion and intracellular replication in the intestinal mucosa. Bacterial invasion is detected by the host innate immune system and triggers a stereotypical, inflammatory response characterized by recruitment of immune cells to the infected tissue. In a remarkable paper, Knodler et al. (2010) propose a novel mechanism by which the intestinal epithelium can clear Salmonella-infected cells through a form of proinflammatory cell death and how Salmonella in fact may exploit this mechanism.

\section{TAKING ONE FOR THE TEAM: PYROPTOTIC CELL DEATH OF INFECTED EPITHELIAL CELLS AS A \\ PROINFLAMMATORY SIGNAL}

Using a polarized epithelial cell culture model, Knodler et al. (2010) observed that in a fraction of infected cells, Salmonella enterica serovar Typhimurium (S. Typhimurium) replicated with an astonishing doubling time of only $20 \mathrm{~min}$. Although conventional wisdom holds that intracellular Salmonella typically reside in a vacuolar compartment, this population had escaped the membrane bound compartment by unknown mechanisms and was replicating rapidly inside the cytoplasm. Epithelial cells harboring hyperreplicating bacteria were expelled from the monolayer into the luminal space. This process resembled the homeostatic turnover of epithelial cells in the intestinal tract. However, during infection with a pathogen, extrusion of dying, infected cells was accompanied by activation of caspase-1, and secretion of the caspase-1 substrate interleukin (IL)-18, a proinflammatory cytokine (Figure 1). This observation suggests that a proinflammatory programmed (pyroptotic) cell death of epithelial cells may contribute to the induction of inflammatory responses in vivo. Indeed, in a murine model of Salmonella-induced colitis, Muller et al. (2009) have shown recently that SopE, a translocated effector of the invasion-associated type three secretion system, triggers intestinal inflammation by activating caspase- 1 in intestinal stromal cells, presumably enterocytes. IL-18 signaling downstream of caspase-1 was required for SopE-mediated induction of inflammation. Taken together, these findings support the idea that pyroptotic cell death contributes to the initiation of the inflammatory host response in the gut (Bergsbaken et al., 2009) and suggest that intestinal epithelial cells serve as sentinels for bacterial invasion.

\section{EXPLOITATION OF HOST IMMUNE RESPONSES BY SALMONELLA}

The inflammatory response induced by $S$. Typhimurium leads to profound changes in the intestinal tract, turning the gut lumen into a nutritional niche in which $S$. Typhimurium efficiently outcompetes the endogenous microbiota (Stecher et al., 2007; Winter et al., 2010). Interestingly, Knodler et al. (2010) also observed that S. Typhimurium might exploit the pyroptotic cell death of bacteria-laden epithelial cells for its own benefit. S. Typhimurium rapidly replicating inside the cytosol of extruded epithelial cells expressed flagella and the invasion-associated type III secretion system, two key virulence factors for invasion of non-phagocytic host cells. Expression of these virulence factors might prime a subpopulation of released bacteria for re-entry into other epithelial cells, thereby prolonging the duration of disease. Furthermore, epithelial pyroptosis might aid in reseeding the intestinal lumen, thereby contributing to transmission by the fecal oral route.

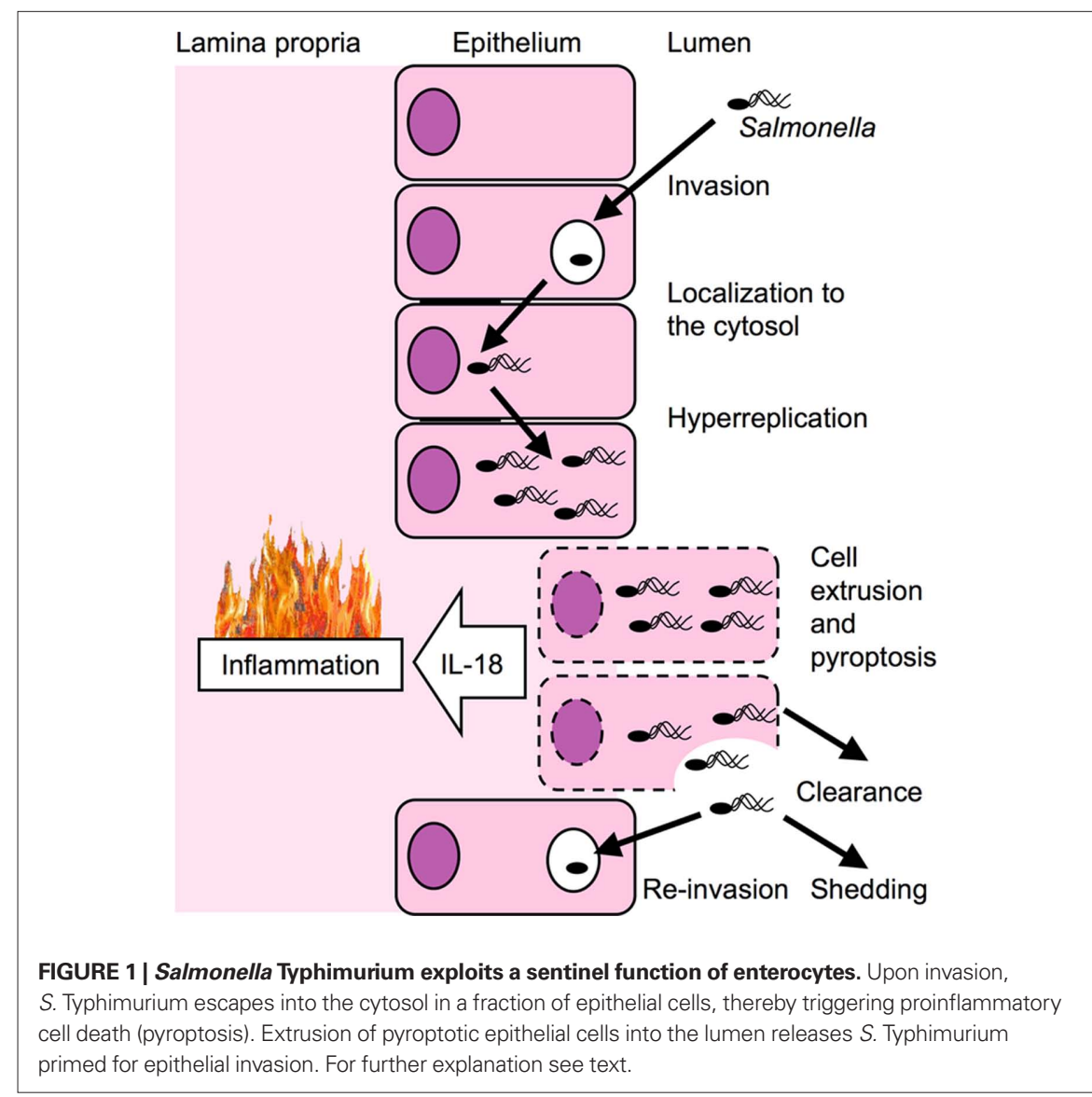


This work by Knodler et al. (2010) is pioneering since it sheds light on a new mechanism of host response aimed at clearing invasive pathogens from the intestinal epithelium and initiating intestinal inflammation. At the same time, the experiments suggest that $S$. Typhimurium may take advantage of this pathway to enhance its transmission success.

\section{REFERENCES}

Bergsbaken, T., Fink, S. L., and Cookson, B. T. (2009). Pyroptosis: host cell death and inflammation. Nat. Rev. Microbiol. 7, 99-109.

Knodler, L. A., Vallance, B. A., Celli, J., Winfree, S., Hansen, B., Montero, M., and Steele-Mortimer, O. (2010).
Dissemination of invasive Salmonella via bacterialinduced extrusion of mucosal epithelia. Proc. Natl. Acad. Sci. U.S.A. 107, 17733-17738.

Muller, A. J., Hoffmann, C., Galle, M., Van Den Broeke, A., Heikenwalder, M., Falter, L., Misselwitz, B., Kremer, M., Beyaert, R., and Hardt, W. D. (2009). The $S$. Typhimurium effector SopE induces caspase-1 activation in stromal cells to initiate gut inflammation. Cell Host Microbe 6, 125-136.

Stecher, B., Robbiani, R., Walker, A. W., Westendorf, A. M., Barthel, M., Kremer, M., Chaffron, S., Macpherson, A. J., Buer, J., Parkhill, J., Dougan, G., von Mering, C., and Hardt, W. D. (2007). Salmonella enterica serovar typhimurium exploits inflammation to compete with the intestinal microbiota. PLoS Biol. 5, 2177-2189. doi: 10.1371/journal.pbio.0050244

Winter, S. E., Thiennimitr, P., Winter, M. G., Butler, B. P., Huseby, D. L., Crawford, R. W., Russell, J. M., Bevins,
C. L., Adams, L. G., Tsolis, R. M., Roth, J. R., and Baumler, A. J. (2010). Gut inflammation provides a respiratory electron acceptor for Salmonella. Nature $467,426-429$.

Received: 25 February 2011; accepted: 03 March 2011; published online: 18 March 2011.

Citation: Winter SE and Bäumler AJ (2011) Salmonella exploits suicidal behavior of epithelial cells. Front. Microbio. 2:48. doi: 10.3389/fmicb.2011.00048

This article was submitted to Frontiers in Cellular and Infection Microbiology, a specialty of Frontiers in Microbiology.

Copyright $\odot 2011$ Winter and Bäumler. This is an openaccess article subject to an exclusive license agreement between the authors and Frontiers Media SA, which permits unrestricted use, distribution, and reproduction in any medium, provided the original authors and source are credited. 